\title{
Adrenal insufficiency in septic shock
}

\author{
Mark Hatherill, Shane M Tibby, Tom Hilliard, Charles Turner, Ian A Murdoch
}

\begin{abstract}
Background-Functional adrenal insufficiency has been documented in critically ill adults.

Objective-To document the incidence of adrenal insufficiency in children with septic shock, and to evaluate its effect on catecholamine requirements, duration of intensive care, and mortality.

Setting-Sixteen-bed paediatric intensive care unit in a university hospital.

Methods-Thirty three children with septic shock were enrolled. Adrenal function was assessed by the maximum cortisol response after synthetic adrenocorticotropin stimulation (short Synacthen test). Insufficiency was defined as a post-Synacthen cortisol increment $<200 \mathrm{nmol} / 1$.
\end{abstract}

Results-Overall mortality was $33 \%$. The incidence of adrenal insufficiency was $52 \%$ and children with adrenal insufficiency were significantly older and tended to have higher paediatric risk of mortality scores. They also required higher dose vasopressors for haemodynamic stability. In the survivor group, those with adrenal insufficiency needed a longer period of inotropic support than those with normal function (median, $3 v 2$ days), but there was no significant difference in duration of ventilation (median, 4 days for each group) or length of stay (median, $5 v 4$ days). Mortality was not significantly greater in children with adrenal insufficiency than in those with adequate adrenal function (6 of $17 v 5$ of 16, respectively).

Conclusion-Adrenal insufficiency is common in children with septic shock. It is associated with an increased vasopressor requirement and duration of shock. (Arch Dis Child 1999;80:51-55)

Keywords: adrenal insufficiency; cortisol; septic shock; mortality; vasopressors

Paediatric Intensive Care Unit, Guy's Hospital, St Thomas's Street, London

SE1 9RT, UK

$M$ Hatherill

S M Tibby

T Hilliard

C Turner

I A Murdoch

Correspondence to: Dr Hatherill.

email: m.hatherill@

umds.ac.uk

Accepted 21 August 1998 effects of glucocorticoids. ${ }^{13-15}$ The possibili that septic shock patients with adrenal insufficiency might benefit from steroid treatment underlines the importance of defining this condition in the paediatric population. We present a prospective observational study of adrenal function in children with septic shock.

\section{Patients and methods}

We enrolled all children admitted to our 16 bed paediatric intensive care unit between May 1996 and April 1997 with a diagnosis of septic shock. We defined septic shock according to the criteria of Saez-Llorens as: hypotension or poor capillary refill responding to fluid or pharmacological intervention in the presence of hyperthermia or hypothermia, tachycardia, tachypnoea, and either leucocytosis or leucopenia; and at least one of the following: acute mental changes, hypoxaemia, hyperlactataemia, and oliguria. ${ }^{16}$ Age, diagnosis, inotrope dose required to maintain mean blood pressure within the normal range for age (2 SD from the mean), average daily therapeutic intervention scoring system (TISS) score ${ }^{17}$ admission multiorgan failure (MOF) score, ${ }^{18}$ paediatric risk of mortality (PRISM) score, calculated risk of mortality, ${ }^{19}$ and outcome were recorded for each patient. Duration of shock (continued inotrope requirement), positive pressure ventilation, and intensive care stay were recorded for the survivor group.

Adrenal function was assessed by the cortisol response to synthetic adrenocorticotropin (ACTH) stimulation. Immediately after admission, $2 \mathrm{ml}$ of blood was taken for baseline cortisol measurement, and the short Synacthen test (Ciba Laboratories, Horsham, UK) was performed using a dose of $145 \mu \mathrm{g} / \mathrm{m}^{2}$ surface area, to a maximum of $250 \mu \mathrm{g}$. Blood samples were repeated at 30 and 60 minutes. Serum was spun immediately, stored at $-60^{\circ} \mathrm{C}$, and measured by chemoluminescence immunoassay (Nichols Institute Diagnostics, San Juan Capistrano, California, USA). Intraassay and interassay coefficients of variation are given as $<5 \%$ and $<10 \%$, respectively. The peak cortisol concentration was taken to be the maximum concentration at either 30 or 60 minutes, and the cortisol increment was calculated as the peak minus baseline value. The results of the Synacthen tests were not made available to the attending medical staff. Adrenal failure was defined as baseline cortisol $<100 \mathrm{nmol} / 1$ and adrenal insufficiency was categorised according to historically accepted criteria (table 1). ${ }^{1-4-8}{ }^{20}$ For the purpose of further analysis, adrenal insufficiency was defined, a priori, as post-Synacthen cortisol increment $<200 \mathrm{nmol} / \mathrm{l}$, because this definition is the one applied most consistently to the critically ill. ${ }^{4-7}$ 
Table 1 Incidence of adrenal insufficiency in our study group $(n=33)$ according to the various published definitions

\begin{tabular}{llcc}
\hline & & \multicolumn{2}{c}{ Adrenal insufficiency } \\
\cline { 3 - 4 } $\begin{array}{l}\text { Definition of adrenal insufficiency } \\
\text { (cortisol, } n \text { nmolll) }\end{array}$ & Reference & Number & Per cent \\
\hline Baseline $<100$ & 3 & 1 & 3 \\
Increment $<200$ & $4-7$ & 17 & 52 \\
Increment $<250$ & 4,8 & 18 & 55 \\
Peak $<500$ & $1,2,4$ & 4 & 12 \\
Peak $<500$ plus increment $<200$ & 6 & 4 & 12 \\
Peak $<$ (baseline $\times 2)$ & 2,20 & 28 & 85 \\
\hline
\end{tabular}

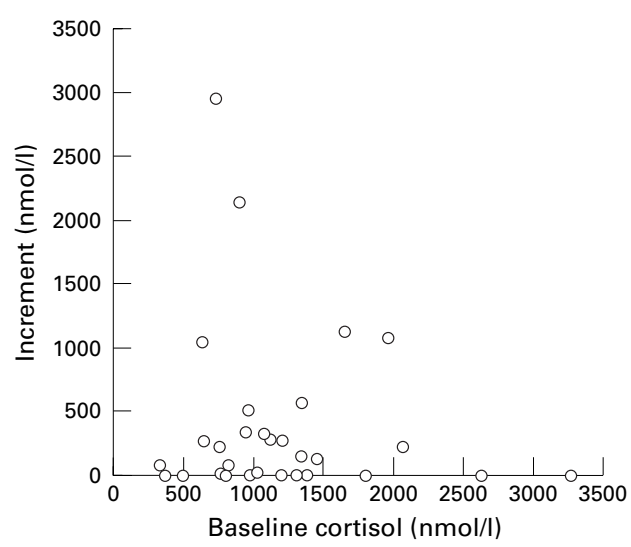

Figure 1 Baseline cortisol (nmol/l) and post-Synacthen cortisol increment in children with septic shock.

We devised a vasopressor score to reflect the vasopressor effect of inotropes used in our clinical practice. Patients were classified according to three ranges of inotrope dose:

(1) Dopamine $\leqslant 10 \mu \mathrm{g} / \mathrm{kg} / \mathrm{min} \pm$ dobutamine any dose

(2) Dopamine $>10 \mu \mathrm{g} / \mathrm{kg} / \mathrm{min}$ and $/$ or adrenaline $\leqslant 0.5 \mu \mathrm{g} / \mathrm{kg} / \mathrm{min}$

(3) Adrenaline $>0.5 \mu \mathrm{g} / \mathrm{kg} / \mathrm{min}$ or noradrenaline any dose

Haemodynamic measurements were performed within 24 hours of admission in 16 patients (seven non-responders and nine responders). Cardiac index and systemic vascular resistance index were determined using femoral artery thermodilution (COLD Z-021; Pulsion Medical Systems, Munich, Germany). ${ }^{21}$ All children were treated according to routine unit management protocols.

We enrolled 33 children (22 survivors; 11 non-survivors), with a median age of 48 months (range, 1-192) and a median PRISM of 17 (range, 4-36). Diagnoses included septicaemia as a result of Neisseria meningitidis $(\mathrm{n}=16)$; Staphylococcus aureus $(\mathrm{n}=4)$; group B streptococcus ( $\mathrm{n}=2)$; Streptococcus pneumoniae $(\mathrm{n}=1)$; and Escherichia coli $(\mathrm{n}=2)$,

Table 2 Children with adrenal insufficiency or adequate adrenal response

\begin{tabular}{llll}
\hline & $\begin{array}{l}\text { Adrenal insufficiency group } \\
(n=17)\end{array}$ & $\begin{array}{l}\text { Adequate adrenal } \\
\text { response group }(n=16)\end{array}$ & p value \\
\hline Age (months) & $109(5-192)$ & $18(1-152)$ & 0.002 \\
Baseline cortisol (nmol/1) & $1018(30-3264)$ & $1083(637-4553)$ & 0.66 \\
Average daily TISS score & $37(21-49)$ & $33(15-54)$ & 0.12 \\
Admission MOF score & $2(1-4)$ & $1.5(0-4)$ & 0.36 \\
PRISM score & $18(9-36)$ & $12(4-26)$ & 0.06 \\
Risk of mortality (\%) & $17(7-29)$ & $7(3-22)$ & 0.12 \\
Mortality (n) & $6(35 \%)$ & $5(31 \%)$ & 1.0 \\
\hline
\end{tabular}

Data are median (range) except for mortality.

TISS, therapeutic intervention scoring system; MOF, multiorgan failure; PRISM, paediatric risk of mortality. secondary to appendicitis and sickle cell disease, respectively; and blood culture negative septic shock $(\mathrm{n}=8)$. $^{10}$

Our study was approved by the hospital ethics committee. Data are presented as median (range) and were analysed by the MannWhitney test, Fisher's exact test, and the $\chi^{2}$ test for trend.

\section{Results}

The incidence of adrenal insufficiency according to accepted criteria (table 1) ranged from $12 \%$ to $85 \%$, whereas the incidence according to the a priori definition (increment $<200$ $\mathrm{nmol} / \mathrm{l}$ ) was $52 \%$. Median cortisol concentrations at baseline and after Synacthen stimulation were similar to concentrations seen in adults with septic shock-that is, baseline $1054 \mathrm{nmol} / 1$ (range, 30-4553) and peak $1398 \mathrm{nmol} / 1$ (range, 378-5128). There was no significant relation between baseline cortisol and post-Synacthen increment in these children (fig 1).

Table 2 shows median age, baseline cortisol, average daily TISS score, admission MOF score, PRISM score, calculated risk of mortality, and observed mortality for the patients with adrenal insufficiency and those with an adequate adrenal response. The former were older and tended to have a worse disease severity score, but this difference was not significant. Average daily TISS and admission multiorgan failure scores did not differ between the two groups. Median calculated risk of mortality corrected for age was $17 \%$ (range, 7-29\%) in adrenal insufficiency compared with $7 \%$ (range, 3-22\%) in those with adequate adrenal function $(p=0.128)$. Mortality was similar in both groups ( $\operatorname{six}$ of $17 v$ five of $16 ; \mathrm{p}=1.0$ ).

Five of the 17 children with adrenal insufficiency required haemofiltration compared with two of the 16 children with adequate adrenal function $(\mathrm{p}=0.39)$. The incidence of Gram negative sepsis was no greater in adrenal insufficiency $(p=1.0)$. Table 3 shows its incidence and mortality in children with Gram negative septicaemia, Gram positive septicaemia, and blood culture negative septic shock.

Children with adrenal insufficiency were more likely to require adrenaline or noradrenaline for haemodynamic support $(p=0.032$; odds ratio $6.1 ; 95 \%$ confidence interval, 1.2 to 30.1). Application of the vasopressor score (table 4) showed a significant linear trend for them to require a greater vasopressor dose ( $p=0.0025 ; \chi^{2}$ test for trend). We subsequently applied the sepsis related organ failure assessment score used in adult practice, ${ }^{22}$ and showed the same linear trend $(p=0.023)$. In the 22 survivors, the median time to resolution of shock (no further inotrope requirement) was 3 days (range, 1-12) in adrenal insufficiency compared with 2 days (range, $0-4$ ) in children with adequate adrenal function $(p=0.008)$. However, there was no significant difference in median duration of ventilation (4 days for both groups; $\mathrm{p}=0.94$ ) or intensive care stay (5 $v 4$ days; $p=0.56$ ). 
Table 3 Adrenal insufficiency and mortality according to diagnostic category in 33 children

\begin{tabular}{|c|c|c|c|c|c|}
\hline \multirow[b]{2}{*}{ Diagnostic category } & \multirow[b]{2}{*}{$n$} & \multicolumn{2}{|l|}{ Incidence } & \multicolumn{2}{|l|}{ Mortality } \\
\hline & & $\begin{array}{l}\text { Adrenal } \\
\text { insufficiency }\end{array}$ & $\begin{array}{l}\text { Adequate } \\
\text { adrenal } \\
\text { funciton }\end{array}$ & $\begin{array}{l}\text { Adrenal } \\
\text { insufficiency }\end{array}$ & $\begin{array}{l}\text { Adequate } \\
\text { adrenal } \\
\text { function }\end{array}$ \\
\hline Gram negative septicaemia & 18 & $10 / 18$ & $8 / 18$ & $2 / 10$ & $1 / 8$ \\
\hline Gram positive septicaemia & 7 & $3 / 7$ & $4 / 7$ & $2 / 3$ & $2 / 4$ \\
\hline Culture negative septic shock & 8 & $4 / 8$ & $4 / 8$ & $2 / 4$ & $2 / 4$ \\
\hline
\end{tabular}

Table 4 Number of children with adrenal insufficiency or an adequate adrenal response in three categories of ascending vasopressor dosage

\begin{tabular}{|c|c|c|c|}
\hline & \multicolumn{3}{|c|}{ Inotrope dose $(\mu \mathrm{g} / \mathrm{kg} / \mathrm{min})$} \\
\hline & $\begin{array}{l}\text { Dopamine } \leqslant 10 \\
\pm \text { dobutamine }\end{array}$ & $\begin{array}{l}\text { Dopamine }>10 \\
\text { adrenaline } \leqslant 0.5\end{array}$ & $\begin{array}{l}\text { Adrenaline }>0.5 \\
\text { noradrenaline }\end{array}$ \\
\hline Vasopressor score & 1 & 2 & 3 \\
\hline Adrenal insufficiency $(\mathrm{n}=17)$ & 0 & 6 & 11 \\
\hline Adequate adrenal response $(n=16)$ & 4 & 9 & 3 \\
\hline
\end{tabular}

Adrenal insufficiency $v$ adequate adrenal response $\mathrm{p}=0.0025\left(\chi^{2}\right.$ test for trend).

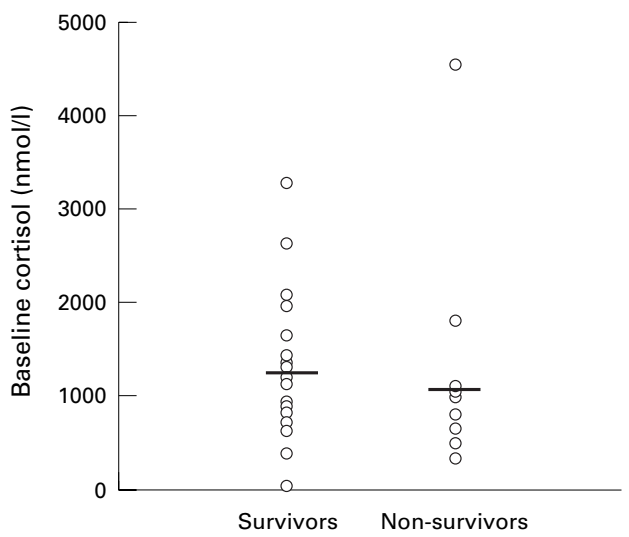

Figure 2 Baseline cortisol (nmol/l) in survivors and non-survivors. Data are expressed as individual values and median ( $p=0.25$; Mann-Whitney test).

Median cardiac index was $6.1 \mathrm{1} / \mathrm{min} / \mathrm{m}^{2}$ compared with $4.851 / \mathrm{min} / \mathrm{m}^{2}(\mathrm{p}=0.07)$, and systemic vascular resistance index was 797 dyn.s $/ \mathrm{cm}^{5} / \mathrm{m}^{2}$ compared with 803 dyn.s/ $\mathrm{cm}^{5} / \mathrm{m}^{2}(\mathrm{p}=1.0)$ in the groups of children with insufficiency and adequate adrenal responses, respectively. Normal ranges are given as $3.5-5.51 / \mathrm{min} / \mathrm{m}^{2}$ for cardiac index and 800 1600 dyn.s $/ \mathrm{cm}^{5} / \mathrm{m}^{2}$ for systemic vascular resistance index.

There was no significant difference between survivors and non-survivors in median baseline cortisol (1198 v $957 \mathrm{nmol} / 1$, respectively; $\mathrm{p}=0.25)$, increment $(223 v 73 \mathrm{nmol} / 1$, respectively; $\mathrm{p}=0.64)$, or peak concentration (1463 $v 1376 \mathrm{nmol} / \mathrm{l}$, respectively; $\mathrm{p}=0.41$ ) (fig 2 ). One patient had overt adrenal failure (baseline cortisol, $30 \mathrm{nmol} / \mathrm{l}$ ) and required parenteral steroid treatment. A subsequent Synacthen test on treatment revealed a post-Synacthen increment of $0 \mathrm{nmol} / \mathrm{l}$. Therefore, this patient was classified as a non-responder.

\section{Discussion}

Our motivation for performing this study lies in the controversy surrounding the use of steroid treatment in patients with septic shock. Despite encouraging animal work and early clinical trials, ${ }^{23}$ several large, placebo controlled, adult studies have reported no benefit from high dose steroids in sepsis. ${ }^{10}$ A meta-analysis concluded that steroid treatment did not improve mortality and that there was an increase in mortality from secondary infection. ${ }^{12}$

However, these investigators made no distinction between patients with normal or abnormal adrenal function. Recent studies demonstrated the existence of occult or functional adrenal insufficiency in septic shock, where either the circulating cortisol or the response to additional ACTH stimulation is inadequate for the stress of the condition. ${ }^{1-4}$ This might be a result of suppression of cortisol production by sepsis rather than adrenal ischaemia, and studies have shown both decreased ACTH receptor binding and interruption of pregnenolone synthesis in the presence of endotoxin and tumour necrosis factor. ${ }^{24}{ }^{25}$ For these reasons, we decided to evaluate adrenocortical rather than pituitary/ hypothalamic function, and measured the response to Synacthen stimulation in preference to ACTH concentrations.

Functional adrenal insufficiency can present as high output cardiac failure, especially under conditions of hypovolaemia, and thus increase the need for vasopressor support in septic shock. ${ }^{313}$ This finding renewed interest in the haemodynamic effects of steroids, because glucocorticoids might both increase myocardial $\beta$ receptor density and inhibit inducible nitric oxide synthase in the presence of endotoxin. ${ }^{14} 26$ Subsequent adult studies have demonstrated reduced inotrope requirement, more rapid resolution of shock, and reduced mortality in patients treated with supplemental steroids. ${ }^{15} 27$ Because patients with septic shock and adrenal insufficiency might be expected to benefit most from treatment, by reducing the hypothetical morbidity related to the adverse effects of vasopressors on the renal and hepatosplanchnic circulation, it is important to define the incidence of this condition in children with septic shock.

Our data show that its incidence might vary widely according to published criteria. We used a post-Synacthen increment of $<200 \mathrm{nmol} / \mathrm{l}$, the definition applied most consistently to the critically ill, ${ }^{4-7}$ and showed a relation between biochemical and functional insufficiency in this group of children. Using this definition, we report an incidence of $52 \%$. A peak post-Synacthen cortisol of $<500 \mathrm{nmol} / 1$ is the definition applied commonly to the general population, as well as by some authors to septic patients, on the basis that a high baseline cortisol is associated with a low increment. ${ }^{98}$ However, we showed no such relation in children with septic shock. The loose definition of adrenal insufficiency used in general paediatric practice (peak cortisol less than twice baseline) would give an incidence of $85 \%$ in our patients, and we suggest that these criteria are inappropriate for critically ill children. ${ }^{20}$ We were also surprised to identify one patient with overt adrenal failure-this child was subsequently placed on maintenance steroid treatment. 
We suspect that the discrepancy between the low calculated risk of mortality in both groups $(7 \%$ and $17 \%)$ and the observed mortality $(31 \%$ and $35 \%)$ might reflect a weakness in the PRISM score. ${ }^{19}$ All patients were transferred from district hospitals by a paediatric retrieval team, and because PRISM is based upon the first 24 hours of PICU physiological data, pre-admission stabilisation might result in artificially low PRISM scores. We are unable to explain why adrenal insufficiency should be more common in older children-the incidence of Gram negative infection did not increase with age. There was no evidence of adrenal infarction (Waterhouse-Friderichsen syndrome) in any of the four non-survivors who underwent postmortem examination.

Although affected children had a higher cardiac index, this difference was not significant, nor was their systemic vascular resistance index lower than the group with adequate adrenal function. This could be because the effects of volume resuscitation and vasopressors masked the high output failure at the time measurements were performed. Our findings that these children have both a greater vasopressor requirement and a longer duration of shock care supported by adult studies. ${ }^{2} 329$

We expected the increased use of catecholamines in children with insufficiency to cause greater morbidity and mortality as a result of renal and hepatosplanchnic vasoconstriction, but this hypothesis was not supported by our data. We showed a trend for them to have a higher disease severity score ${ }^{19}$ but they did not have a higher rate of organ failure. ${ }^{18}$ Although the therapeutic end points we used to reflect morbidity could be criticised as relatively imprecise markers of end organ damage, we note that children with adrenal insufficiency did not require greater intensive care support, as shown by their TISS score, ${ }^{17}$ need for haemofiltration, duration of ventilation, and intensive care stay. In particular, they did not have a higher mortality rate. This implies either that the haemodynamic consequences may be treated with high dose vasopressors without additional ill effect, or that the power of our study was insufficient to detect a true increase in mortality. A much larger study population would be required to resolve this issue.

The beneficial effects of steroid treatment, reported recently in adults raise the question of whether a placebo controlled trial should be undertaken in children. ${ }^{141527}$ Do our data provide an objective rationale for a trial of supplemental steroids in children with septic shock? We have proposed that children with adrenal insufficiency might be those who would most benefit from such treatment, and we have shown that it has a high incidence in our study population. However, the primary end point of any trial of steroid treatment in such children should be mortality. Based on our study population, a trial having sufficient power to detect a reduction in mortality from $30 \%$ to $15 \%$ would require at least 500 children with septic shock. Nevertheless, despite the logistical problems, the association between adrenal insufficiency and additional haemodynamic instability evident from our data suggests that a trial of low dose supplementary steroids in septic shock may be warranted.

\section{CONCLUSION}

Our study shows an appreciable incidence of adrenal insufficiency in children with septic shock, and we note that these patients require higher doses of catecholamines for a longer period to maintain haemodynamic stability. Our data suggest that to answer the controversial question of whether supplementary steroids improve mortality in these children, a study population of more than 500 patients would be required.

1 Soni A, Pepper GM, Wyrwinski PM, et al. Adrenal insufficiency occurring during septic shock: incidence, outcome, and relationship to peripheral cytokine levels. $A m \mathcal{F}$ Med 1995;98:266-71.

2 Baldwin WA, Allo M. Occult hypoadrenalism in critically ill patients. Arch Surg 1993;128:673-6.

3 Quiney NF, Durkin MA. Adrenocortical failure in intensive care. BMF 1995;310:1253-4

4 Bouachour G, Tirot P, Gouello JP, Mathiieu E, Vincent JF, Alquier PH. Adrenocortical function during septic shock. Intensive Care Med 1995;21:57-62.

5 Briegel J, Schelling G, Haller M, Mraz W, Forst H, Peter K. A comparison of the adrenocortical response during septic shock and after complete recovery. Intensive Care Med 1996;22:894-9.

6 Moran JL, Chapman MJ, O'Fathertaigh MS, Peisach AR, Pannall PR, Leppard P. Hypocortisolaemia and adrenocortical responsiveness at onset of septic shock. Intensive Care tical responsiveness at

7 McWhinney PHM, Patel A, Walker E. Adrenal failure in McWhinney PHM, Patel A, Walker E. Adrenal failure in
fulminant meningococcal septicaemia: a clinical reality. fulminant meningococcal septica

8 Rothwell PM, Udwadia ZF, Lawler PG. Cortisol response to corticotropin and survival in septic shock. Lancet 1991; 337;582-3.

9 May ME, Carey RM. Rapid adrenocorticotropic hormone test in practice. Am $\mathcal{F}$ Med 1985;79:679-84.

0 Bone RC, Fisher CJ, Clemmer TP, Slotman GJ, Metz CA, Balk RA. A controlled trial of high-dose methylprednisolone in the treatment of severe sepsis and septic shock. N Engl F Med 1987;317:653-8.

11 Veterans Administration Systemic Sepsis Cooperative Study Group. Effect of high-dose glucocorticoid therapy on mortality in patients with clinical signs of systemic sepsis. $N$ tality in patients with clinical
Engl f Med $1987 ; 317 ; 659-65$.

12 Cronin L, Cook DJ, Carlet J, et al. Corticosteroid treatment for sepsis: critical appraisal and meta-analysis of the literature. Crit Care Med 1995;23:1430-9.

13 Bouachour G, Tirot P, Varache N, Gouello JP, Harry P, Alquier PH. Hemodynamic changes in acute adrenal insufficiency. Intensive Care Med 1994;20:138-41.

14 Saito T, Takanashi M, Gallagher E, et al. Corticosteroid effect on early beta-adrenergic down-regulation during circulatory shock: hemodynamic study and beta-adrenergic receptor assay. Intensive Care Med 1995;21:204-10.

5 Bollaert PE, Charpentier C, Levy B, Debouverie M, Audibert GA, Larcan A. Reversal of late septic shock with supraphysiologic doses of hydrocortisone. Crit Care Med 1998;26:645-50.

16 Saez-Llorens X, McCracken GH. Sepsis syndrome and septic shock in pediatrics: current concepts of terminology, pathophysiology, and management. f Pediatr 1993;123: pathophys.

17 Keene AR, Cullen DJ. Therapeutic intervention scoring system: update 1983. Crit Care Med 1983;11:1-3.

18 Wilkinson JD, Pollack MM, Glass NL, Kanter RK, Katz RW, Steinhart CM. Mortality associated with multiple organ system failure and sepsis in the pediatric intensive care unit. F Pediatr 1987;111:324-8.

19 Pollack MM, Ruttiman UE, Getson PR. Pediatric risk of mortality (PRISM) score. Crit Care Med 1988;16:1110-16.

20 Oski FA, DeAngelis CD, Feigin RD, McMillan JA, Warshaw JB, eds. Principles and practice of pediatrics. Philadelphia: JB Lippincott, 1994.

21 Tibby SM, Hatherill M, Marsh MJ, Morrison G, Anderson D, Murdoch IA. Clinical validation of cardiac output measurements using femoral artery thermodilution with direct Fick in ventilated children and infants. Intensive Care Med 1997;23:987-91.

22 Vincent JL, Moreno R, Takala J, et al. The SOFA (sepsis-related organ failure assessment) score to describe organ dysfunction/failure. Intensive Care Med 1996;22:70710 .

23 Schumer W. Steroids in the treatment of clinical septic shock. Ann Surg 1976;184:333-41. 
24 Catalano RD, Parameswaran V, Ramachandran J, Trunkey DD. Mechanisms of adrenocortical depression during Escherichia coli shock. Arch Surg 1984;119:145-9.

25 Jaattela M, Ilvesmaki V, Voutilainen R, Stenman U, Saksela E. Tumor necrosis factor as a potent inhibitor of adrenocorticotropin-induced cortisol production and steroidogenic P450 enzyme gene expression in cultured human fetal adrenal cells. Endocrinology 1991;128:623-9.

26 Szabo C. Alterations in nitric oxide production in various forms of circulatory shock. New Horizons 1995;3:2-32.
27 Spijkstra JJ, Schreuder WO. Beneficial effects of corticosteroids in septic shock. Intensive Care Med 1995;21(suppl): steroids.

28 Grinspoon SK, Biller BMK. Laboratory assessment of adrenal insufficiency. F Clin Endocrinol Metab 1994;79:92331 .

29 Glorieux D, Laterre PF, Evenepoel M, Dugernier T, Florence E, Reynaert MS. Spectrum of cortisol response in sepsis. Correlation with degree of illness and mortality. Intensive Care Med 1994;20(suppl):S22.

\section{Mouldy homes and bleeding lungs}

The importance of dampness in the home in relation to applications for rehousing is often debated. An intriguing piece of medical detective work in Cleveland, Ohio, USA (Ruth A Etzel and colleagues, Archives of Pediatrics and Adolescent Medicine 1998;152:757-62) has demonstrated an apparently rare but startling effect of home dampness on infants.

Over two years (1993-94) 10 infants (all black, nine boys) were admitted to a children's hospital with acute pulmonary haemorrhage and haemosiderosis; there had been just three such cases in the previous 10 years. The presenting features were acute haemoptysis with lethargy, sudden cessation of crying, pallor, limpness, and respiratory failure. All of the babies were severely ill and needed intensive care, nine were intubated, and one died. Five had to be readmitted because of another episode up to six months after discharge. The diagnosis was confirmed in all cases by lung biopsy or bronchial lavage. All of the babies lived in one area of the city and there was a common history of water damage to the home from leaking roofs, plumbing leaks, or flooding. Some of the infants had evidence of haemolysis and this, together with the epidemiological features, led investigators to consider the possibility of a haemolytic toxin producing fungus. They investigated specifically for Stachybotrys atra, a fungus known to grow in damp conditions and to produce a toxin that causes bleeding and haemolysis in animals.

They examined the homes of nine of the 10 infants and 28 of 30 age and locality matched controls. Mean colony counts for all fungi in air were more than 40 times greater in the patients' homes than in those of controls. Counts of $S$ atra were 10 times higher in the air, and 3000 times higher on surfaces, in patients' homes compared with controls'. The patients were also more likely to have been exposed to tobacco smoke in the home. Surveys have shown $S$ atra in up to 3\% of North American homes. In this outbreak the babies with acute pulmonary haemorrhage were much more likely than control babies to have been exposed to high concentrations of $S$ atra. The association has not been proved to be one of cause and effect but the evidence seems highly suggestive. 